\title{
A glimpse of hope: cardiac surgery in low- and middle-income countries (LMICs)
}

\author{
Peter Zilla ${ }^{1}$, R. Morton Bolman III $^{2}$, Percy Boateng ${ }^{3}$, Karen Sliwa ${ }^{4}$ \\ ${ }^{1}$ Christian Barnard Department for Cardiothoracic Surgery, University of Cape Town and Groote Schuur Hospital, Cape Town, South Africa; \\ ${ }^{2}$ Anschutz Medical Campus, University of Colorado Denver, Aurora and University of Colorado, Denver, CO, USA; ${ }^{3}$ Department of Cardiovascular \\ Surgery, Icahn School of Medicine, Mount Sinai (ISMMS) Medical Center, New York, NY, USA; ${ }^{4}$ Hatter Institute for Cardiovascular Research in \\ Africa, Department of Medicine, Faculty of Health Sciences, Groote Schuur Hospital, University of Cape Town, Cape Town, South Africa \\ Contributions: (I) Conception and design: P Zilla; (II) Administrative support: All authors; (III) Provision of study materials or patients: None; (IV) \\ Collection and assembly of data: All authors; (V) Data analysis and interpretation: P Zilla; (VI) Manuscript writing: All authors; (VII) Final approval \\ of manuscript: All authors. \\ Correspondence to: Peter Zilla. Christian Barnard Department of Cardiothoracic Surgery, University of Cape Town, Cape Town, South Africa. \\ Email: peter.zilla@uct.ac.za.
}

\begin{abstract}
Currently, more than five times more people live in low- and middle-income countries (LMICs) than in high-income countries (HICs). As such, the downward trend in cardiac surgical needs in HICs reflects only the situation of one sixth of the world population while the vast majority living in LMICs has still no or limited access to life saving heart operations. In these countries, rheumatic heart disease (RHD) still accounts for a significant proportion of cardiac surgical needs. In low- and lower-middle income countries it remains the single most common cardiovascular disease in young adult and adolescent patients in need of heart surgery outweighing other indications such as congenital cardiac defects almost 4-fold. Compared to HICs with their predominance of calcific aortic stenosis in the elderly mitral valve surgery is required in $>90 \%$ of the largely young patients with RHD in low-income countries (LICs) and still in $70 \%$ of the often middle aged patients in middle-income countries (MICs). Although recent government initiatives in LICs led to the establishment of local, independent cardiac surgical services gradually replacing fly-in missions, these centers still only cover less than $2 \%$ of the needs of their populations. In MICs, cardiac surgical needs continually grow with the emergence of degenerative diseases. As such, in spite of the concomitant growth of cardiac surgical capacity, significantly less than half the estimated patients in need have access. Capacities in LICs range from 0.5 to 7 cardiac operations/million population; 100-481/million in MICs and >1,200/million in HICs such as the USA and Germany. While a new level of awareness of the scope and magnitude of the problem has begun to emerge in LICs and the establishment of local cardiac surgical capacity has given rise to a glimpse of hope, the challenges of expanding these fledgling services to a significant proportion of the population still seem insurmountable. Challenges in MICs are on the other hand the widening gap between private cardiac medicine for the affluent few and overwhelmed public services for the many and the rural urban divide with the underappreciation of the ongoing dominance of RHD in the rural and indigent population on the other. Overshadowing all LMICs is the low level of valverepair skills associated with insufficient cardiac surgical capacity and the unavailability of suitable replacement valves which address the young age of the patients and the difficulties of anticoagulation in a socioeconomic environment distinctly different from the elderly patients of HICs.
\end{abstract}

Keywords: Cardiac surgical needs; operative capacity; low- and middle-income countries (LMICs)

Submitted Aug 28, 2019. Accepted for publication Nov 04, 2019.

doi: $10.21037 / \mathrm{cdt} .2019 .11 .03$

View this article at: http://dx.doi.org/10.21037/cdt.2019.11.03 


\section{Introduction}

In spite of an ongoing paucity of life-saving cardiac surgery in developing, low-income countries (LICs) $(1,2)$ a growing awareness for the role of non-communicable diseases (NCDs) in these regions has led to a new determination towards addressing unmet needs. Low- and lower-middle-income countries like Mozambique, Sudan, Tanzania, Zimbabwe, Zambia, Cote D’Ivoire, Uganda, Ethiopia, Namibia, Senegal, Ghana, Kenya or Bangladesh have all made the significant first step of establishing local cardiac surgeries that function independent from fly-in missions (3-7).

Other countries like Rwanda have demonstrated the feasibility of open-heart surgery (8) and have trained their first "local" cardiac surgeon in South Africa, and even societies as remote as Myanmar's have identified and quantified the need for open-heart surgery (9). Along with this development, the international cardiac surgical community has recently united behind efforts to assist these fledgling programs (10-12).

Having gone through this stage sometimes as early as in the 1960 s and 1970s $(2,7,13,14)$ middle-income countries (MICs) from the Maghreb to South Asia and from Latin America to North-East Asia have impressively expanded their cardiac surgical capacity in the last two decades (2) but still woefully lag behind the needs of their populations.

While low- and middle-income countries (LMICs) provide very different levels of cardiac surgical services for their populations, they still share challenges highincome countries (HICs) have long left behind. Foremost, both underlying pathologies and the socioeconomic circumstances of significant parts of the population remain so distinctly different from HICs that neither established hospital systems nor surgery itself can be uncritically mirrorreplicated from industrialized countries. While urbanization has led to a slow but steady shift towards degenerative cardiovascular diseases, the single dominant pathology driving the need for open-heart surgery in LMICs is still rheumatic heart disease (RHD) (1,2,4,7,14-23). Although congenital cardiac defects take center stage from an emotive point of view, RHD remains the most common cardiovascular disease in young adult and adolescent patients (24-27) requiring surgery in Sub-Saharan Africa $(15,16,18,19)$ and LICs globally $(14,17,20-23)$. They are usually young, poor, uneducated, and often have difficulty in accessing medical care (28). As such, even for those patients who have access to cardiac surgery, low compliance rates with anticoagulation therapy lead to a significantly increased incidence of lethal or debilitating complications after heart valve replacement (29-34).

Therefore, the task of providing cardiac surgery in LMICs involves much more than establishing expensive infrastructure and scarce skills. Surgery for simple congenital defects is often the driving starting point, but more complex cases need to wait for large metropolitan centres to emerge at a late stage of development. Surgery for RHD is in a similar, if not more difficult situation: heart valve replacement often stands at the beginning of a program, but the cost of prostheses is often prohibitive, and poor outcome $(16,29-31,34,35)$ makes repair rather than replacement even more desirable than in HICs (36-42). Yet, valve repair is a skill that builds on the experience of a seasoned team, and, as such, is often absent where it is needed most. Last but not least, the appearance of degenerative diseases in MICs largely correlates with urbanisation and affluence. The requirement of a more sophisticated infrastructure and again of expensive, imported consumables for concomitant balloon angioplasty and stenting initially leads to only the rich being treated overseas, followed by a proliferation of local private facilities for those who can afford it.

In LICs, whether cardiac surgery is offered at all and at what level largely depends on four major determinants: (I) the commitment of governments and their available resources; (II) the primary health care systems which are often inadequate and fail in their front-line role towards prophylaxis and diagnostic surveillance; (III) socioeconomic conditions that trigger RHD in the first place and are partly responsible for the poor outcome after surgery and (IV) the highly specialised discipline of cardiac surgery itself, whose requirements are different from the way it is practised in the industrialised world.

With health care insurance schemes either seriously underdeveloped or absent in LICs (43), the lion's share of costs needs to be paid out of pocket (6). Although a fraction of what open-heart surgery would cost in industrialised countries (43) 6,000-10,000 USD for valve procedures $(3,6,43)$ are beyond the reach of $>90 \%$ of the population $(6)$. Since public subsidies can be predicted to remain meagre for the foreseeable future, viable high through-put centres for the significant number of indigent patients in need will be unlikely to materialise soon.

In MICs, further factors are the rural-urban divide and the fast-growing disparity between private health care for the affluent and an overwhelmed public sector for the indigent majority. South Africa is a case in point, where 
42 private cardiac surgeries serve 10 million people with private insurances while only seven centres provide the only available service for the remaining indigent 48 millions. Variations in any of these determinants may cause huge disparities in cardiac surgical services between countries in similar per capita GDP brackets. Nigeria's 0.5 operations per million (Ops/mio) are opposed by 177 Ops/mio in the Maghreb countries, both listed in similar GDP ranks. Nigeria is the most extreme lower-middle-income country with cardiac surgery barely existent for its population of 200 million in spite of a heavy burden of RHD $(44,45)$. In this case, government commitment is the main reason for the difference. Similarly, Brazil and China are both uppermiddle-income countries with almost identical per-capita GDPs. The 2.5 times higher number of cardiac operations per million population offered in Brazil is most likely based on the more extreme urban/rural divide of China ( $41 \%$ of the population still live in rural areas versus $13 \%$ in Brazil). With an average of 300 open heart operations per year and centre in China (as opposed to 1,200 in Germany), 53\% of hospitals perform fewer than 100 operations/year. These are also the hospitals in the more rural areas where RHD is still prevalent. Differently put, $75 \%$ of all patients are operated in the $21 \%$ urban hospitals performing $>300$ cases per year. Conversely, the $42 \%$ of the population living in rural areas get only $25 \%$ of all cardiac operations, incidentally, in hospitals largely providing fewer than 100 cases per year (2). This picture is further accentuated by the fact that China still only delivers $30 \%$ of what its population needs, in spite of boasting the world's largest heart centres in its metropolitan areas, corresponding with about one eighth of Western European or North American levels of heart surgery (2).

\section{Patients in need of cardiac surgery and patient's needs}

Principally, the basic cardiac surgical operations are similar in LICs and HICs. What is different is the underlying pathology, the prevalence of procedures and the algorithms that should be followed. Here, the epidemiologic transition from communicable diseases in LICs to NCDs in HICs directly correlates with a shift from RHD to degenerative cardiovascular diseases. This is notwithstanding the conundrum RHD faces of strictly not belonging to communicable diseases. This shift from rheumatic valve pathologies to a predominantly arteriosclerotic and degenerative burden of disease is also associated with a quantitative increase in patients requiring cardiac surgery - and that in spite of the continually expanding role interventional cardiology plays.

Therefore, the overall number of patients requiring cardiac surgery in LICs is almost 4 times lower than in HICs due to a steep increase in degenerative diseases in contradistinction to a flatter decline in rheumatic patients in MICs (2) in the course of the epidemiologic and socioeconomic transition from developing to industrialised country (Figure 1). The major exception to this development is the surgical needs for congenital heart defects (CHD), where the global burden of disease is believed to be relatively constant (46-50) (Figure 1). However, as this observation relates to "live births" the de-facto incidence in CHD is higher in a country like the Chad where the crude birth rate is 43 as opposed to Italy where it is less than 8 . There are also factors real and circumstantial that lessen the needs in LICs. For one, the significantly lower levels of postnatal diagnosis in LICs need to be taken into account. At the same time, it is a disheartening reality that those $30 \%$ of children with CHD suffering from complex defects would either die undiagnosed or remain trapped in the lower level of the referral system in the absence of highly specialised referral centres. Under the line, the dramatic difference in birth rates outweighs the moderating factors in these countries. As such, the theoretical need for congenital cardiac surgery in LICs is approximately 1.1-1.3 times higher (80-110/million population/year) (2) than the level currently provided by countries like the UK or Germany (60-95/million population/year) (50-54). This number is still relatively low as it is based on the assumption that only the "simple" $70 \%$ of defects [atrial septal defects (ASDs), ventricular septal defects (VSDs); atrioventricular septal defects (AVSDs); tetralogies] will realistically be considered (55).

Opposite these relatively well-defined needs for congenital cardiac surgery, RHD would still be the dominant indication for heart surgery in adults and adolescents $(1,2,4,7,14-27)$. With an overall need ranging from between 200-250 Ops/mio in endemic regions of South Asia and Sub-Saharan Africa and 300-400 Ops/mio in endemic hot spots of Ozeania, RHD outweighs other indications 3-4:1 (2) (Figure 1). These patients' needs are very different from those of heart valve patients in HICs. The typical septua- to nonagenarians of industrialised countries require primarily aortic valve surgery [in the USA $1.3 \times(56)$ and $1.6 \times(57)$ the number of mitral valve operations and in Germany 2.2× (58)] (Figure 2). Rheumatic patients, 


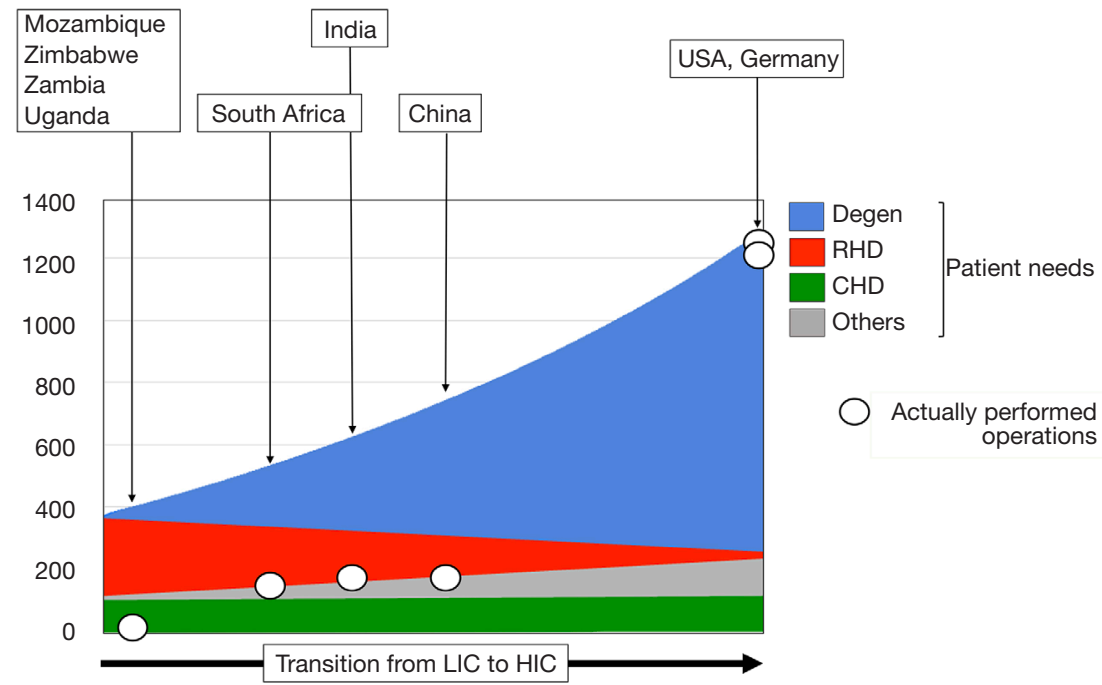

Figure 1 Gap between de-facto performed cardiac operations per million population (black lined white circles) and estimated patients in need of cardiac surgery (4-colour graph). The colours differentiate between operations needed for degenerative and life-style diseases (DEGEN) (e.g., coronary bypass operations; aortic valve replacement for calcific aortic stenosis); rheumatic heart disease (RHD); congenital heart defects (CHD) and other diseases affecting the heart and the aorta (OTHERS). From left to right reflects the changing needs as countries gradually transition from developing low-income countries (LICs) to industrialised high-income countries (HICs). While the incidence of CHD remains relatively unaffected by this transition, that of RHD declines as that of degenerative diseases increases. The 4-fold overall increase of non-congenital cardiac surgical needs during the transition from LIC to HIC is the result of a non-linear increase in degenerative diseases. Estimates of the respective positions of typical representatives of LICs, MICs and HICs on this graph were based on key indicators such as proportion of coronary artery bypass procedures and urbanization (2). Total numbers reflect the status-quo of 2017 (2). The congruence of needs and operations performed in the USA and Germany highlights the fact that affluence can eventually close a gap that does not only prevail in LICs but also MICs. [amended from (2) with permission].

in contrast, are younger and dominated by mitral pathology (Figure 2). In the "Heart of Soweto Study" Sliwa et al. report a $71 \%$ prevalence of mitral valve surgery in newly diagnosed urban patients with RHD (median age 41 years) (60) and Zuhlke et al. found the mitral valve significantly involved in $>96 \%$ of patients of the "REMEDY" study, analysing symptomatic patients with RHD from 14 LMICs in Africa and Asia (Figure 2). In this cohort, one third presented in heart failure (median age 28 years) (59). In patients where surgery was not an option (either not available or too late) $57 \%$ were younger than 30 years. One third of these had pure mitral regurgitation. If one added the patients with mixed mitral valve pathology, $42 \%$ of patients had single mitral valve disease with predominantly regurgitation (59). As the leaflets of mitral valves with mixed rheumatic disease are pliable in three quarters of patients in this age group, the vast majority would therefore have been repairable, if the service and requisite skills had been available. This need for facilities and skills capable of providing mitral valve repair becomes even more pressing in view of another $52 \%$ in the younger-than-30 group suffering from double valve disease (59). In this group, mitral valve repair is often indicated in spite of the aortic valve undergoing a replacement procedure. The data from the REMEDY study correspond with a study from Myanmar in a cohort of largely surgical patients. It confirmed mitral valve involvement in $96 \%$ of patients and isolated mitral valve disease in $59 \%$ (9). Highlighting once more the central role of the mitral valve in surgery for RHD, pioneers like Alain Carpentier (61), Sampath Kumar (62) and Taweesak Chotivatanapong (63) have shown that mitral repair can be offered to nearly all such patients. Yet, even though the Saigon program of Carpentier demonstrated that repair can commence at an early stage of the de novo establishment of cardiac surgery, the intense support this particular program encountered from the mentoring institution in Paris may not allow a generalisation to other, less fortunate sites.

Although a far second behind the mitral valve, rheumatic 


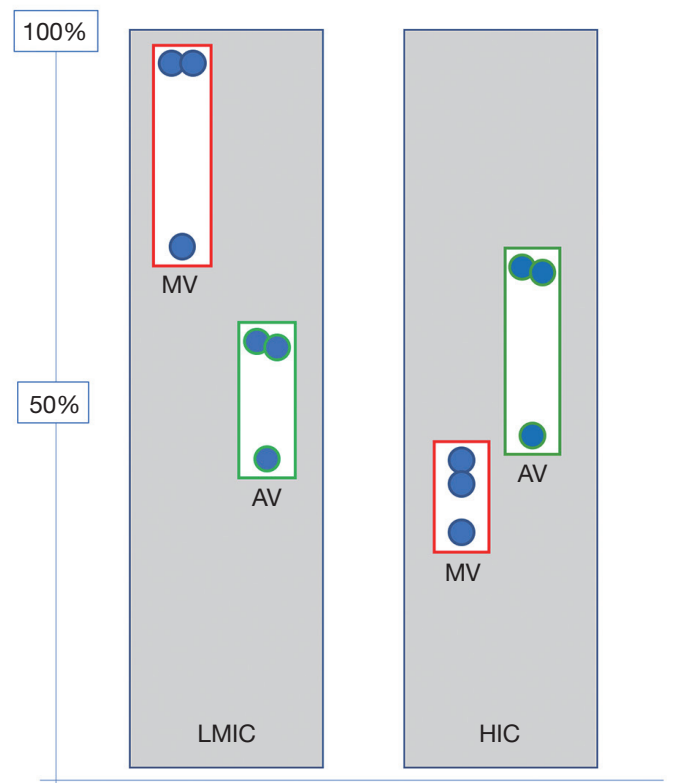

Figure 2 Percentage of patients undergoing heart valve surgery who need mitral/aortic valve interventions in LMICs versus HICs. The largely rheumatic pathology in LICs would require mitral valve interventions in almost all patients presenting for surgery below the age of $30(9,59)$ and in three quarters of urban middleaged patients in MICs (60). Although aortic valve surgery is still required in half of all patients with RHD, 9 out of 10 of these also need mitral valve replacement/repair $(59,60)$. In contrast, in the mostly elderly patients of HICs with their typically degenerative diseases, the aortic valve is the primarily affected heart valve-in a majority without co-affecting the mitral valve (56-58). LMICs, low- and middle-income countries; HICs, high-income countries; LICs, low-income countries; RHD, rheumatic heart disease; AV, aortic valve; $M V$, mitral valve.

aortic valve disease is present in between $30 \%$ and $41 \%$ of cases of RHD needing surgery (Figure 2). As it causes a more serious impact on left ventricular function, quality of life and overall prognosis $(9,64)$ recent evidence supports rather early intervention for aortic regurgitation (AR) before the setting of irreversible myocardial damage. In contrast to mitral valve disease it poses both a diastolic as well as a systolic volume overload, thereby causing early irreversible damage (65). While isolated mitral valve disease occurs in 6 out of 10 patients requiring surgical intervention, only 1 in 10 patients with rheumatic aortic valve disease has not also got the mitral valve involved $(9,59)$. Again, the preference of repairs over replacements also applies to the aortic valve, but successful repair procedures using autologous pericardium were only recently introduced in HICs (66) where pathologies are largely not complicated by a chronic inflammatory process. Magdi Yacoub's group in Aswan pioneered aortic valve repair in rheumatic patients (64) by applying on the aortic valve a "shaving" method Sampath Kumar had introduced to the repair of thickened, fibrotic mitral valves (67) and Taweesak Chotivatanapong (63) had popularised since. Similar to the slow uptake of modern mitral valve repair after its introduction $>40$ years ago, however, it will take time until aortic valve repair will be widely accepted by the established cardiac surgical community. Then, a similar conundrum to mitral valve repairs will confront LICs, namely the need for experienced, seasoned surgeons in the absence of basic cardiac services. Accordingly, repairneeds will not even be remotely met in the foreseeable future. Until then, valve replacement surgery will remain an imperfect but life-saving therapy for a majority of centres. The particular challenges of heart valve replacement in LMICs lie in the young age of the patients and their socioeconomic circumstances. Both make contemporary valve prostheses a suboptimal choice. While bioprosthetic heart valves degenerate faster in young patients than in older ones $(68,69)$, mechanical prostheses are also poorly suited due to suboptimal access to international normalized ratio (INR) control $(29,31,70)$ (Figure 3). Although there is consensus on these two baseline axioms, guidelines and algorithms keep being applied that were developed for the industrialised world (72), leading most likely to too many patients receiving mechanical prostheses in LMICs. The absence of large databases and often cardiac surgical services all together explains why LMICS haven't worked out their own algorithms. However, algorithms are only the back-side of the coin. The front side is the realisation that prostheses that are acceptable for the elderly recipients of HICs are simply not good enough for the prevailing circumstances of LIMCs (73). In the 1990s, a simple vilification of the core cross-link agent glutaraldehyde (74) had started to give way to a deeper understanding of the bioprosthetic degeneration processes (73). The realisation that remnant immunogenicity was the single most dominant mechanism of premature tissue valve failure $(75,76)$ led to intensified efforts towards antigen extraction either through decellularization $(77,78)$ or partial cell membrane extraction with alcohols (79-83). With the focus on the transcatheter delivery of soft-leaflet heart valves (for the time being still synonymous with bioprosthetic valves), 

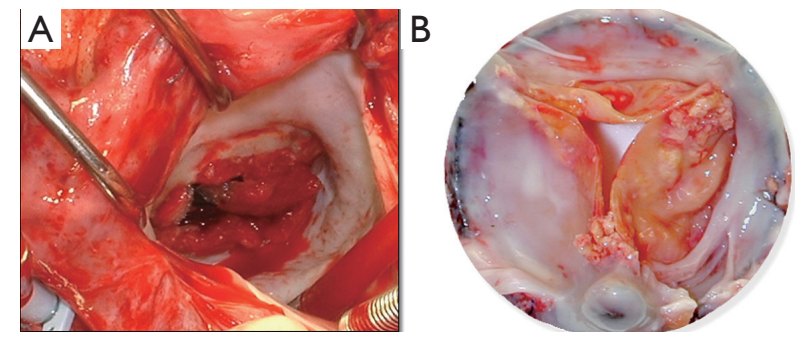

Figure 3 Poor suitability for LMICs of heart valve prostheses that were developed for the epidemiologic and socioeconomic circumstances of patients from HICs. (A) Typical emergency operation for a clotted mechanical valve prosthesis inserted in a young rheumatic patients from a poor socioeconomic background (reproduced from Eur Heart 7 with permission) (71); (B) degenerated bioprosthetic heart valve after four and a half years of implantation in a 28-year-old woman with rheumatic heart disease whose anticipated ability to comply with anticoagulation was low. Leaflet immobilisation through calcification was additionally aggravated by pannus overgrowth. LMICs, low- and middleincome countries; HICs, high-income countries.

however, research into bioprosthetic longevity moved to the back-burner, but some of the early insights of the preceding era have cautiously been translated into contemporary tissue valves. Partial phospholipid membrane extraction with alcohols, for instance, has found its way into some commercial tissue valves. LivaNova uses octanediol-ethanol for its FREE treatment, St. Jude/Abbot uses ethanol for its Linx-treatment of its Trifecta valve and so does Edwards Life-Sciences in its Thermafix heat treatment used for its Perimount valves (84). Single centre, long-term studies with these valves have shown remarkably encouraging results in young patients (85). Yet, given the scarcity of such studies, and their unconfirmed findings by the broader cardiac surgical community controversy will continue to hamper the wider use of tissue valves in the younger patients of LICs. Together with the dearth of cardiac surgery in affected countries, the reluctance of ethics committees to endorse tissue valve studies in the young and the "safe" path of following European and North American guidelines, it is unlikely that significant studies-not to mention tailormade guidelines-will emerge that change the unsatisfying choice of replacement heart valves in LICs in the near future. Until then, many more of those lucky enough to get the benefit of cardiac surgery at all will experience the detrimental complications of mechanical prostheses in an environment that is simply not geared for anticoagulation.
Alternatively, they might get tissue valves that may continue to prematurely fail due to research towards true bioprosthetic longevity having stopped half way through as a consequence of the general enthusiasm for trans-catheter delivery routes 20 years ago. It will take a long time until it is generally recognised that regardless of the deployment mode, the question of leaflet durability will eventually have to be answered-not least to also allow HICs to lower the age limit for tissue valves [e.g., transcatheter aortic valve implantations (TAVIs)] and thereby reduce morbidity and improve the quality of life. The real benefactor of such a late realisation of a goal of the 1980s, however, will be LICs with their young and hitherto neglected patients.

In contrast to the undisputed prevalence of RHD as the main cause for patients needing cardiac surgery in LICs, there is often a gap between perception and true needs in MICs. Contrary to the widely held view that MICs have relegated RHD to the history of medicine, MICs still claim a large proportion of the global burden of deaths caused by RHD (China 23\%; India 47\%) (25). The poorly understood increase of patients with RHD who cannot recall a history of acute rheumatic fever (ARF) is partly to blame for this disparity of perception, as ARF has been taken as the official benchmark for RHD for decades. The Maghreb region is not the only example where the officially suggested eradication of ARF is paralleled by a continuously high incidence of patients needing heart valve surgery for RHD that cannot only be explained with a clinical lag-phase (86) However, as much as the cardiac surgical needs of MICs for patients with RHD are still higher than generally perceived, the growing demand for heart surgery in these countries is mainly driven by the epidemiological transition coming with urbanisation and affluence. An additional decline in the incidence of RHD certainly also plays a role. In recent years, the country-wide number of operations needed per million population has doubled in most of the MICs on the back of coronary artery bypass procedures and aortic valve replacement in aging patients with calcific aortic stenosis. While large urban heart centres are testimony to the response of these countries to the epidemiologic transition, the rural and largely indigent part of society often finds itself in a negative feedback loop: governments interpret vanishing numbers of rheumatic fever as indication for an eradication of the disease. Emerging echocardiographic screening-studies (87-94) leave the conclusions open as to how many patients will need surgery. Low detection rates by inadequate primary health care structures suggest a low priority for cardiac surgery to governments. Without a 
referral endpoint, the referral system is discouraged from sending patients for cardiac surgery even if they were successfully identified on the primary health care level. As such, MICs are in the most challenged middle position of needing cardiac surgery for pathologies and demographics of both LICs and HICs while still being in a relatively early phase of establishing heart surgery.

\section{Evolving cardiac surgical services}

In all LICs heart surgery started with fly-in missions from industrialised countries $(3,10,11,13,14,95-97)$. The very first heart operations performed by outside teams can often be traced back several decades. In Nigeria it was in 1974 at the University of Nigeria, Nsukka (Sir Magdi Yacoub being the surgeon); in Uganda in 1969 at Kampala's Mulago Hospital; in Kenya in 1973 at the Kenyatta National Hospital in Nairobi; in Zambia at the UTH Lusaka in 1994 by a team from Uzbekistan and in Rwanda in 2006 at the King Faisal Hospital Kigali by an Australian team-to just mention a few. Conversely, various non-governmental organizations (NGOs) arranged operations for children from developing countries in HICs such as the USA or Israel (96). Minneapolis-based "Children's Heart Link" for instance began flying Vietnamese children to Minneapolis for surgery from as early as 1969 (98). Similarly, Israelbased "Save a Child's Heart" began flying children from 48 countries including Tanzania, Ethiopia (99-101), Senegal, Côte d'Ivoire, Sierra Leone and others (101) for surgery. Similarly, some governments of LICs decided to send patients to MICs like India or South Africa for their heart operations. The question as to whether these fly-in or flyout missions have benefitted a few while harming the many is a controversial topic of ongoing debates. While one may argue that these missions could be seen as trial-runs for the sophisticated infrastructure and interdisciplinary skillsharmonisation necessary for commencing local open-heart surgery, the long-term verdict is largely less positive. In the long run, overseas missions-financed by NGOs or their governments and mostly deploying big teams for a handful of predominantly congenital corrections-provided the local governments with fig leaves. Being able to superficially claim that heart surgery was offered to their population, the gap between the population's needs for life-saving surgery and the actually offered miniscule relief for society as a whole could be camouflaged.

Today, there is reason for hope. In recent years, most African countries have either managed to commence programs independent of fly-in missions, or are in the process of doing so. Overall, capacities still fall far short of the demand for surgery. With current capacities of LICs like Mozambique, Zimbabwe or Zambia in the region of 1.5 to $4 \mathrm{Ops} / \mathrm{mio}$ (Figure 4) (2), they under-deliver at least by a factor 50 to 100 (Figure 5). However, it does make a huge difference whether everything including skills is in place, or whether it would otherwise need to be established from scratch. The recent alliance of the major global cardiac surgical societies towards a coordinated assistance is another promising development (10-12). Growing awareness for the importance of training sites mirroring local pathologies also had an impact. Other than in the past when expertise was striven to be acquired at prestigious universities in industrialised countries, most of the newly established programs have relied on training in MICs like India or South Africa. As these host countries provide exposure to both shared pathologies like RHD and the way they are surgically treated, they better reflect the needs of a LIC. More importantly, these middle-income host countries also teach how to successfully maintain cardiac surgery with limited resources. To close the delivery-gap for the indigent population that cannot afford treatment overseas, many more things will need to fall in place. Government commitment to resource allocation in a poor country will be one critical factor. Active assistance by industrialised countries which can supply the near-unaffordable consumables will be another. What is most encouraging is that almost all of these fledgling programs are tied to a longterm commitment. Some governments have already been funding skills-training in preparation for local programs for many years. Even more promising is the fact that almost all of these programs are truly government-driven not hiding privileged access for the few behind disingenuous buzzwords such as "private-public-partnerships".

In MICs, developments were historically very different. Local cardiac surgical abilities were established almost as early as in HICs. In Brazil, the first open heart operations on cardiopulmonary bypass were performed in 1956, in China in Xi'an in 1958 (by 1964, 20 hospitals were doing open-heart surgery), in South Africa by Christiaan Barnard in 1958, and in Mumbai in 1961 (2). In spite of early support for these programs (in Brazil the first heart transplant was performed in Sao Paulo in 1968, 6 months after Chris Barnard's), fast-growing patient needs as a consequence of population growth and epidemiologic transition outpaced efforts to catch up. Since then, the Indian population grew by a factor $3 \times$, the Chinese by $2.3 \times$, the South African by 


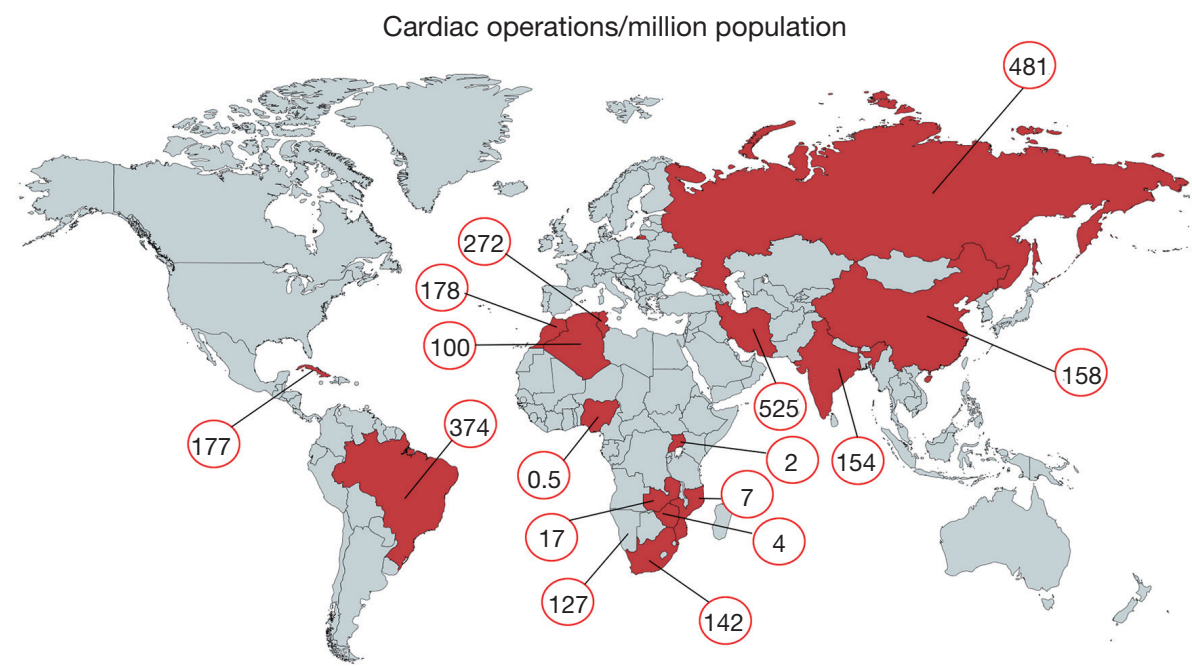

Figure 4 Cardiac surgical operations per million population assessing 16 LMICs comprising 3.6 billion inhabitants. Numbers were derived from a global study determining needs in 2017 (2). LMICs, low- and middle-income countries.

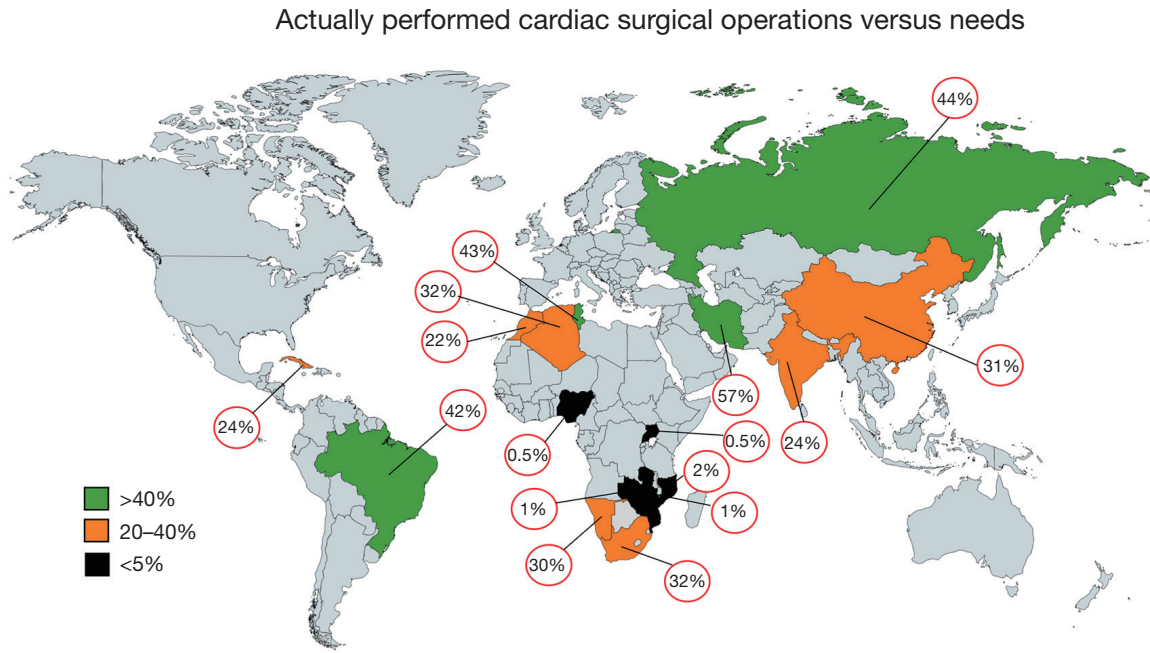

Figure 5 Level of actually performed cardiac surgery related to the individual needs of a country. The percentages depicted represent mean values thereby masking country-specific social, geographic or political diversities. In countries with a high Gini index like South Africa, for instance, the overall $32 \%$ of the population with access to heart operations comprise the $83 \%$ who depend on public services and have a low access level of $20 \%$ and the $17 \%$ on private medical aid with practically $100 \%$ access to cardiac surgery. It equally does not take geographic differences into account. In Russia, for instance, all cardiac surgery is offered in public hospitals. Yet, the 44\% represent a mean value between diverse regions such as the North-West and the Caucasus. In spite of this underlying heterogenicity of the national situations the mean values of the included countries correlate with their developmental status.

$2.8 \times$ and the Brazilian by $3.3 \times$. At the same time overall per-million population needs for non-congenital cardiac surgery increased due to the epidemiologic transition by approximately a factor 1.9 for India and South Africa and 3.4 for China (2) (Figure 1). As such, capacity needs grew 5 to 8 times since the establishment of first independent cardiac surgical outposts. However, these are just two of the aspects affecting the level of cardiac surgery provided in MICs. 
Another one is urbanisation. Naturally, a highly specialised service such as open-heart surgery needs physical proximity of patients and facilities for many reasons, from the critical density of allied specialists to travel-distances for patients for diagnosis, referral and follow-up. Since urbanisation also means earlier entry into the epidemiologic transition, urban patients have a higher incidence of degenerative disease than rural ones. As a consequence, expertise in the country naturally begins to become biased against diseases like RHD which dominate in rural areas and in the lowest social levels of urban dwellings where the epidemiologic transition arrives last. In China, only 17 patients/million undergo heart valve surgery for RHD although population needs are in the region of 55/million (Figure 5). In India, the underdelivery of heart valve surgery for RHD is by a factor 10 . As such, annually, almost 80,000 patients in China and 130,000 in India suffering from symptomatic RHD are not receiving surgery.

In MICs of comparable high per capita GDP (8-9 K) urbanisation may play a role. If one compares China and Brazil, an urbanisation of $59 \%$ versus $87 \%$ corresponds with 158 versus 374 cardiac operations per million population (2) (Figure 4). In lower MICs (1.7-4 K per capita GDP), however, urbanisation does not seem to correlate with cardiac surgical service levels. In three countries with a low urbanisation of less than $50 \%$, cardiac surgery varied widely: India $154 \mathrm{Ops} / \mathrm{mio}$; Namibia $88 \mathrm{Ops} / \mathrm{mio}$ and Nigeria 0.5 Ops/mio (2) (Figure 4). What does seem to be a strong factor influencing service levels-or simply reflecting them-is inequality. This is not necessarily visible from socioeconomic indicators like the Gini index where the most unequal society of South Africa (Gini index 68) and one of the least unequal societies like India (Gini index 35) share similar levels of cardiac surgery (159 versus $154 \mathrm{Ops} / \mathrm{mio}$ ). Yet, if equal access to cardiac surgery for all levels of society is taken into consideration, the biggest service discrepancies do not occur between different countries but emerge between the public and the private sector within a country. At the extreme end is South Africa, where those $17 \%$ of the population with access to private medicine (Figure 6) receive 12 times more operations per million population than those $83 \%$ who depend on the public sector (2). Differently looked at, one private hospital cares for 300,000 cardiac surgical patients compared to 6.1 million patients per centre in the public sector. Similarly, 7.1 cardiac surgeons provide surgery per million private patients as opposed by 0.7 in public hospitals (2). Although increasingly strained, the state insurance system ("Unified Health System" SUS) in
Brazil, in contrast, covers $83 \%$ of the population in $100 \%$ of hospitals providing almost identical levels of cardiac surgery in public and private hospitals (376 versus 373 Ops) (2). In Iran (Gini index 39) equality also seems to be the common denominator behind the impressively high and comparable levels of cardiac surgery offered to "public" and "private" patients (568 versus $425 \mathrm{Ops} / \mathrm{mio}$ ) (2). There, the vast majority of all patients are treated almost for free $(10 \%$ in "social security hospitals"; $60 \%$ at university hospitals and $10 \%$ at hospitals belonging to government organisations like the military). The remaining $20 \%$ are "private patients" treated in private hospitals that were founded by doctors (2). In China, where only 5 major private hospitals operate $3 \%$ of all cardiac patients the "urban-rural divide" is at least not augmented by the "public private divide" and in Russia, the fact that all cardiac surgery is done in the public sector may be one reason for a relatively high service level for a MIC (481 Ops/mio). In this vast country, inequality is rather geographic in nature and partly responsible for an overall delivery of cardiac surgery that lies $158 \%$ below that of Germany (2).

\section{Conclusion/way forward}

Cardiac surgery as a discipline is here to stay in LMICs. Wedged between the need to catch up with industrialised countries and the eventual disappearance of the discipline in its traditional form, heart surgery in LMICs will be on a growth trajectory for a long time to come. While it has already started to contract as a surgical specialty in HICs and entered its passage towards a joint "cardiac intervention" platform there, high unmet needs, population growth and the ongoing epidemiologic transition will all require a continual prioritisation of this late-coming discipline both in LICs an MICs. The challenge for MICs will be to not lose sight of the need for surgery for RHD, even though the urban population, with its predominance of degenerative heart diseases, and its command of most of the available resources, obscures the view onto a problem that is still significant. On the positive side, the unique position of MICs also opens the opportunity to have a global impact. Being much more affected by the need for next-generation, better-suited tissue valves (surgical or trans-catheter) $(73,102,103)$ than high income countries with their aging population, the high levels of technological capabilities that have emerged over the past two decades would make them the logical development site for long-lasting biomaterials, something that would eventually benefit rich countries, as 


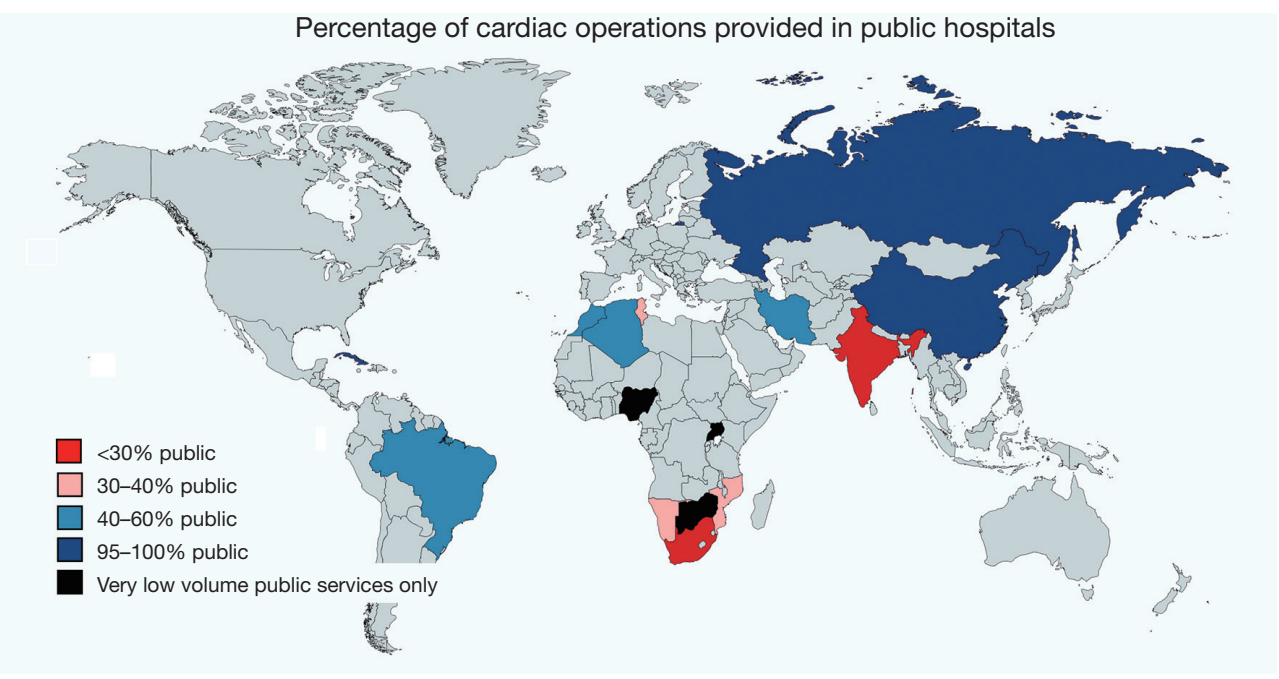

Figure 6 North-South gradient of the role public services play in offering cardiac surgery. In Russia, all heart operations are provided in public hospitals. In China, private cardiac centres are negligible although all of the almost 4,000 cardiovascular surgeons are allowed to work at multiple places (e.g., public and private). The government's medical insurance largely covers $50 \%$ of the medical cost during any admission even in private hospitals and patient contribution is significant also in the public sector. In Brazil, the law provides every citizen with free health-care but the system is strained. As all cardiac centres, public and private, provide surgery to public patients, the state insurance system (Unified Health System) covers open-heart surgery for $83 \%$ of the population in $100 \%$ of hospitals even if a significant proportion of heart centres is private. In India, even in government hospitals, patients still need to contribute 1,000 to 2,000 USD to a cardiac operation as opposed to 3,000 to 5,000 USD in a private facility. Of all cardiac hospitals, $<10 \%$ are public. Government or state employees get part of their expenditure reimbursed if they get operated on in a government-endorsed private hospital. In South Africa, $87 \%$ of the population receive $29 \%$ of all cardiac operations in public hospitals while the remaining $71 \%$ of heart operations are performed on the $17 \%$ private patients in private hospitals (2).

well. For LICs, their progress towards not only establishing their own, independent surgical services, but also expanding them to accommodate a significant proportion of patients in need is vulnerable. Upheavals in the world economy will hit the weakest most and make perceived "luxuries" like heart surgery the obvious targets of forced austerity. Yet, even without such disruptions the expensive nature of consumables produced at high profit margins in the developed world will maintain a degree of dependence in LMICS and MICS that can only be resolved by a collective commitment towards a true partnership rather than oldfashioned aid. A new level of awareness of the scope and magnitude of this problem has begun to emerge, and the commitment of LICs towards the establishment of independently operating cardiac surgeries on the one hand and signs of a new dawn of awareness in HICs such as the "Cardiac Surgery Intersociety Alliance" (CSIA) $(10,11)$ are promising glimpses of hope. Yet, this awareness will need to be matched by a consolidation of cardiac surgical efforts within low-income regions of the world. The recent call for a dialogue of cardiac surgeons on the African continent in the Abidjan declaration is a promising move in this direction (104).

\section{Acknowledgments}

The authors wish to acknowledge the fact that key data on LMICs were based on the initiatives emerging from the Cape Town Declaration $(2,12)$ including the resulting Cardiac Surgery Intersociety Alliance (CSIA) (10-12). The support of CSIA by the World Heart Federation was instrumental.

Funding: None.

\section{Footnote}

Provenance and Peer Review: This article was commissioned by the Guest Editor (Ntobeko A. B. Ntusi) for the series "Cardiovascular Diseases in Low-and Middle-Income Countries" published in Cardiovascular Diagnosis and 
Therapy. The article was sent for external peer review organized by the Guest Editor and the editorial office.

Conflicts of Interest: All authors have completed the ICMJE uniform disclosure form (available at http://dx.doi. org/10.21037/cdt.2019.11.03). The series "Cardiovascular Diseases in Low-and Middle-Income Countries" was commissioned by the editorial office without any funding or sponsorship. The authors have no conflicts of interest to declare.

Ethical Statement: The authors are accountable for all aspects of the work in ensuring that questions related to the accuracy or integrity of any part of the work are appropriately investigated and resolved.

Open Access Statement: This is an Open Access article distributed in accordance with the Creative Commons Attribution-NonCommercial-NoDerivs 4.0 International License (CC BY-NC-ND 4.0), which permits the noncommercial replication and distribution of the article with the strict proviso that no changes or edits are made and the original work is properly cited (including links to both the formal publication through the relevant DOI and the license). See: https://creativecommons.org/licenses/by-nc-nd/4.0/.

\section{References}

1. Sliwa K, Zilla P. Rheumatic heart disease: the tip of the iceberg. Circulation 2012;125:3060-2.

2. Zilla P, Yacoub M, Zühlke L, et al. Global Unmet Needs in Cardiac Surgery. Global Heart 2018;13:293-303.

3. Edwin F, Tettey M, Aniteye E, et al. The development of cardiac surgery in West Africa--the case of Ghana. Pan Afr Med J 2011;9:15.

4. ElSayed A, Elnur EE. The rebirth of cardiac surgery in Sudan. Cardiovasc Diagn Ther 2016;6:S20-6.

5. Ngatchou W, Kamdem F, Lemogoum D, et al. Late mortality after cardiac interventions over 10-year period in two Cameroonian government-owned hospitals. Cardiovasc Diagn Ther 2019;9:43-9.

6. Tettey M, Tamatey M, Edwin F. Cardiothoracic surgical experience in Ghana. Cardiovasc Diagn Ther 2016;6:S64-73.

7. Yangni-Angate KH, Meneas C, Diby F, et al. Cardiac surgery in Africa: a thirty-five year experience on open heart surgery in Cote d'Ivoire. Cardiovasc Diagn Ther 2016;6:S44-63.
8. Rusingiza EK, El-Khatib Z, Hedt-Gauthier B, et al. Outcomes for patients with rheumatic heart disease after cardiac surgery followed at rural district hospitals in Rwanda. Heart 2018;104:1707-13.

9. Myint NP, Aung NM, Win MS, et al. The clinical characteristics of adults with rheumatic heart disease in Yangon, Myanmar: An observational study. PLoS One 2018;13:e0192880.

10. Boateng P, Bolman RM 3rd, Zilla P. Cardiac surgery for the forgotten millions: the way forward. Eur J Cardiothorac Surg 2019;56:217.

11. Call for proposals to be a pilot site for CSIA supported programs. Asian Cardiovasc Thorac Ann 2019;27:339-40.

12. Zilla P, Bolman RM, Yacoub MH, et al. The Cape Town Declaration on Access to Cardiac Surgery in the Developing World. S Afr Med J 2018;108:702-4.

13. Eze JC, Ezemba N. Open-heart surgery in Nigeria: indications and challenges. Tex Heart Inst J 2007;34:8-10.

14. Pezzella AT. On Location-Vietnam. CTSNeT 2017. doi: https://doi.org/10.25373/ctsnet.5475670.

15. Little SG. The challenges of managing rheumatic disease of the mitral valve in Jamaica. Cardiol Young 2014;24:1108-10.

16. Mve Mvondo C, Pugliese M, Ambassa JC, et al. Mechanical Heart Valve Replacement in a Low-Middle Income Region in the Modern Era: Midterm Results from a Sub-Saharan Center. Thorac Cardiovasc Surg 2020;68:99-106.

17. Seckeler MD, Hoke TR. The worldwide epidemiology of acute rheumatic fever and rheumatic heart disease. Clin Epidemiol 2011;3:67-84.

18. Howson CP, Reddy KS, Ryan TJ, et al. The Current Burden of Cardiovascular Diseases in Developing Countries. Control of Cardiovascular Diseases in Developing Countries: Research, Development and Institutional Strengthening. Washington: The National Academic Press, 1998:11-23.

19. Mocumbi AO. Lack of focus on cardiovascular disease in sub-Saharan Africa. Cardiovasc Diagn Ther 2012;2:74-7.

20. Rheumatic Fever and Rheumatic heart disease Geneva 2001. World Health Organisation Technical Report Series No.923.

21. Chin TK, Chin EM. Pediatric Rheumatic Heart Disease. Patnana SR. editor. Medscape 2019:11-23. Available online: https://emedicine.medscape.com/article/891897

22. Kumar RK, Tandon R. Rheumatic fever \& rheumatic heart disease: The last 50 years. Indian J Med Res 2013;137:643-58. 
23. Watson G, Jallow B, Le Doare K, et al. Acute rheumatic fever and rheumatic heart disease in resource-limited settings. Arch Dis Child 2015;100:370-5.

24. Remenyi B, Carapetis J, Wyber R, et al. Position statement of the World Heart Federation on the prevention and control of rheumatic heart disease. Nat Rev Cardiol 2013;10:284-92.

25. Watkins DA, Johnson CO, Colquhoun SM, et al. Global, Regional, and National Burden of Rheumatic Heart Disease, 1990-2015. N Engl J Med 2017;377:713-22.

26. GBD 2013 Mortality and Causes of Death Collaborators. Global, regional, and national age-sex specific all-cause and cause-specific mortality for 240 causes of death, 19902013: a systematic analysis for the Global Burden of Disease Study 2013. Lancet 2015;385:117-71.

27. Global Burden of Disease Study C. Global, regional, and national incidence, prevalence, and years lived with disability for 301 acute and chronic diseases and injuries in 188 countries, 1990-2013: a systematic analysis for the Global Burden of Disease Study 2013. Lancet 2015;386:743-800.

28. Antunes MJ. Challenges in rheumatic valvular disease: Surgical strategies for mitral valve preservation. Glob Cardiol Sci Pract 2015;2015:9.

29. Scherman J, Manganyi R, Human P, et al. Isolated mechanical aortic valve replacement in rheumatic patients in a low- to middle-income country. J Thorac Cardiovasc Surg 2018;157:886-93.

30. Ogendo SW. Long term valve-related morbidity following open-heart surgery at the Kenyatta National Hospital. East Afr Med J 2000;77:199-202.

31. Chalachew T, Yadeta D, Tefera E. Factors associated with sub-optimal control of anticoagulation in patients with prosthetic heart valves taking oral anticoagulants in a subSaharan African setting. Cardiovasc J Afr 2019;30:1-5. [Epub ahead of print].

32. Bowry AD, Shrank WH, Lee JL, et al. A systematic review of adherence to cardiovascular medications in resourcelimited settings. J Gen Intern Med 2011;26:1479-91.

33. Alphonsa A, Sharma KK, Sharma G, et al. Knowledge regarding oral anticoagulation therapy among patients with stroke and those at high risk of thromboembolic events. J Stroke Cerebrovasc Dis 2015;24:668-72.

34. Thomson Mangnall L, Sibbritt D, Fry M, et al. Short- and long-term outcomes after valve replacement surgery for rheumatic heart disease in the South Pacific, conducted by a fly-in/fly-out humanitarian surgical team: a 20-year retrospective study for the years 1991 to 2011. J Thorac Cardiovasc Surg 2014;148:1996-2003.
35. Akhtar RP, Abid AR, Zafar H, et al. Prosthetic valve replacement in adolescents with rheumatic heart disease. Asian Cardiovasc Thorac Ann 2007;15:476-81.

36. Kumar AS. Surgical options in rheumatic mitral valve disease in children: a surgeon's perspective. World J Pediatr Congenit Heart Surg 2014;5:80-4.

37. Talwar S, Saikrishna C, Saxena A, et al. Aortic valve repair for rheumatic aortic valve disease. Ann Thorac Surg 2005;79:1921-5.

38. Antunes MJ. Repair for rheumatic mitral valve disease. The controversy goes on! Heart 2018;104:796-7.

39. Antunes MJ. Repair of rheumatic mitral valve regurgitation: how far can we go? Eur J Cardiothorac Surg 2013;44:689-91.

40. Antunes MJ. Valve repair for rheumatic mitral regurgitation: still worthwhile? J Heart Valve Dis 2011;20:254-6.

41. Grinda JM, Latremouille C, Berrebi AJ, et al. Aortic cusp extension valvuloplasty for rheumatic aortic valve disease: midterm results. Ann Thorac Surg 2002;74:438-43.

42. Grinda JM, Latremouille C, D'Attellis N, et al. Triple valve repair for young rheumatic patients. Eur J Cardiothorac Surg 2002;21:447-52.

43. Falase B, Sanusi M, Majekodunmi A, et al. The cost of open heart surgery in Nigeria. Pan Afr Med J 2013;14:61.

44. Ejim EC, Ubani-Ukoma CB, Nwaneli UC, et al. Common echocardiographic abnormalities in Nigerians of different age groups. Niger J Clin Pract 2013;16:360-4.

45. Ekpe EE, Ikpe MC, Umoh I. Echocardiographic pattern of acquired heart diseases in Nigeria. Niger Med J 2015;56:253-7.

46. Edwin F, Zuhlke L, Farouk H, et al. Status and Challenges of Care in Africa for Adults With Congenital Heart Defects. World J Pediatr Congenit Heart Surg 2017;8:495-501.

47. van der Linde D, Konings EE, Slager MA, et al. Birth prevalence of congenital heart disease worldwide: a systematic review and meta-analysis. J Am Coll Cardiol 2011;58:2241-7.

48. Zühlke L, Mirabel M, Marijon E. Congenital heart disease and rheumatic heart disease in Africa: recent advances and current priorities. Heart 2013;99:1554-61.

49. Mocumbi AO, Lameira E, Yaksh A, et al. Challenges on the management of congenital heart disease in developing countries. Int J Cardiol 2011;148:285-8.

50. Hoffman JI, Kaplan S. The incidence of congenital heart disease. J Am Coll Cardiol 2002;39:1890-900.

51. Hoffman JI. Natural history of congenital heart disease. 
Problems in its assessment with special reference to ventricular septal defects. Circulation 1968;37:97-125.

52. Marijon E, Tivane A, Voicu S, et al. Prevalence of congenital heart disease in schoolchildren of sub-Saharan Africa, Mozambique. Int J Cardiol 2006;113:440-1.

53. Bernstein D. Congenital Heart Disease. In: Behrman RE, Kliegman RM, Jenson HB. editors. Nelson Textbook of Pediatrics. Elsevier, 2004:1501-9.

54. Hoffman JI. Incidence of congenital heart disease: I. Postnatal incidence. Pediatr Cardiol 1995;16:103-13.

55. Edwin F. The future of heart surgery in Ghana. Paper presented to the Walter Sisulu Pediatric Cardiac Foundation; Tintswalo at Waterfall Lodge, December 12, 2009. Available online: http://www.frankedwin.com/wpcontent/uploads/2010/02/Future-of-Heart-Surgery-inGhana.pdf. Accessed May 6, 2011.

56. Adult Cardiac Surgery in New York State 2012-2014. New York State Department of Health. Available online: https:// www.health.ny.gov/statistics/diseases/cardiovascular/ heart_disease/docs/2012-2014_adult_cardiac_surgery.pdf

57. Barnett SD, Ad N. Surgery for aortic and mitral valve disease in the United States: a trend of change in surgical practice between 1998 and 2005. J Thorac Cardiovasc Surg 2009; 137:1422-9.

58. Beckmann A, Meyer R, Lewandowski J, et al. German Heart Surgery Report 2017: The Annual Updated Registry of the German Society for Thoracic and Cardiovascular Surgery. Thorac Cardiovasc Surg 2018;66:608-21.

59. Zühlke L, Karthikeyan G, Engel ME, et al. Clinical Outcomes in 3343 Children and Adults With Rheumatic Heart Disease From 14 Low- and Middle-Income Countries: Two-Year Follow-Up of the Global Rheumatic Heart Disease Registry (the REMEDY Study). Circulation 2016;134:1456-66.

60. Sliwa K, Carrington M, Mayosi BM, et al. Incidence and characteristics of newly diagnosed rheumatic heart disease in urban African adults: insights from the heart of Soweto study. Eur Heart J 2010;31:719-27.

61. Phan KP, Nguyen vP, Pham NV, et al. Mitral valve repair in children using Carpentier's techniques. Semin Thorac Cardiovasc Surg Pediatr Card Surg Annu 1999;2:111-20.

62. Kumar AS, Rao PN. Mitral valve reconstruction: intermediate term results in rheumatic mitral regurgitation. J Heart Valve Dis 1994;3:161-4.

63. Chotivatanapong T, Chaiseri P, Leelataweewud U. Repair of the Mitral Valve Anterior Leaflet: Early Results. Asian Cardiovasc Thorac Ann 1996;4:214-6.

64. Afifi A, Hosny H, Yacoub M. Rheumatic aortic valve disease - when and who to repair? Ann Cardiothorac Surg
2019;8:383-9.

65. Carabello BA. Assessment of the patient with valvular heart disease: An integrative approach. Aswan Heart Cent Sci Pract Ser 2011. doi: http://dx.doi.org/10.5339/ ahcsps.2011.15.

66. Ozaki S, Kawase I, Yamashita H, et al. Midterm outcomes after aortic valve neocuspidization with glutaraldehydetreated autologous pericardium. J Thorac Cardiovasc Surg 2018;155:2379-87.

67. Kumar AS, Talwar S, Saxena A, et al. Results of mitral valve repair in rheumatic mitral regurgitation. Interact Cardiovasc Thorac Surg 2006;5:356-61.

68. Keenan NM, Newland RF, Baker RA, et al. Outcomes of Redo Valve Surgery in Indigenous Australians. Heart Lung Circ 2019;28:1102-11.

69. Chan V, Malas T, Lapierre H, et al. Reoperation of left heart valve bioprostheses according to age at implantation. Circulation 2011;124:S75-80.

70. Thomson Mangnall LJ, Sibbritt DW, Al-Sheyab N, et al. Predictors of warfarin non-adherence in younger adults after valve replacement surgery in the South Pacific. Heart Asia 2016;8:18-23.

71. Sliwa K, Johnson MR, Zilla P, et al. Management of valvular disease in pregnancy: a global perspective. Eur Heart J 2015;36:1078-89.

72. Baumgartner H, Falk V, Bax JJ, et al. 2017 ESC/EACTS Guidelines for the management of valvular heart disease. Eur Heart J 2017;38:2739-91.

73. Zilla P, Brink J, Human P, et al. Prosthetic heart valves: catering for the few. Biomaterials 2008;29:385-406.

74. Gong G, Ling Z, Seifter E, et al. Aldehyde tanning: the villain in bioprosthetic calcification. Eur J Cardiothorac Surg 1991;5:288-99.

75. Human P, Zilla P. Characterization of the immune response to valve bioprostheses and its role in primary tissue failure. Ann Thorac Surg 2001;71:S385-8.

76. Vincentelli A, Latremouille C, Zegdi R, et al. Does glutaraldehyde induce calcification of bioprosthetic tissues? Ann Thorac Surg 1998;66:S255-8.

77. Kim WG, Park JK, Lee WY. Tissue-engineered heart valve leaflets: an effective method of obtaining acellularized valve xenografts. Int J Artif Organs 2002;25:791-7.

78. Cebotari S, Mertsching H, Kallenbach K, et al. Construction of autologous human heart valves based on an acellular allograft matrix. Circulation 2002;106:I63-8.

79. Vyavahare NR, Hirsch D, Lerner E, et al. Prevention of calcification of glutaraldehyde-crosslinked porcine aortic 
cusps by ethanol preincubation: mechanistic studies of protein structure and water-biomaterial relationships. J Biomed Mater Res 1998;40:577-85.

80. Langanki D, Ogle M, Cameron J, et al. Evaluation of a novel bioprosthetic heart valve incorporating anticalcification and antimicrobial technology in a sheep model. J Heart Valve Dis 1998;7:633-8.

81. Meuris B, De Praetere H, Strasly M, et al. A novel tissue treatment to reduce mineralization of bovine pericardial heart valves. J Thorac Cardiovasc Surg 2018;156:197-206.

82. Pettenazzo E, Valente M, Thiene G. Octanediol treatment of glutaraldehyde fixed bovine pericardium: evidence of anticalcification efficacy in the subcutaneous rat model. Eur J Cardiothorac Surg 2008;34:418-22.

83. Pathak CP, Adams AK, Simpson T, et al. Treatment of bioprosthetic heart valve tissue with long chain alcohol solution to lower calcification potential. J Biomed Mater Res A 2004;69:140-4.

84. Padala M. A heart valve is no stronger than its weakest link: The need to improve durability of pericardial leaflets. J Thorac Cardiovasc Surg 2018;156:207-8.

85. Chowdhury UK, Rizvi A, Narang R, et al. Mitral Valve Replacement Using Carpentier-Edwards Pericardial Bioprosthesis in Patients With Rheumatic Heart Disease Aged Below 40 Years: 17-Year Results. Heart Lung Circ 2018;27:864-71.

86. Bouzid A, Chibane S, Bouchenafa S, et al. Undiagnosed Rheumatic Fever: The Submerged Part of The Iceberg. Global Heart 2016;11:e60.

87. Ekure EN, Amadi C, Sokunbi O, et al. Echocardiographic screening of 4107 Nigerian school children for rheumatic heart disease. Trop Med Int Health 2019;24:757-65.

88. Ali S, Domi S, Abbo B, et al. Echocardiographic screening for rheumatic heart disease in 4515 Sudanese school children: marked disparity between two communities. Cardiovasc J Afr 2018;29:273-7.

89. Kotit S, Said K, ElFaramawy A, et al. Prevalence and prognostic value of echocardiographic screening for rheumatic heart disease. Open Heart 2017;4:e000702.

90. Essop MR, Mayosi BM. Echocardiographic Detection of Latent Rheumatic Heart Disease: A Pandora's Box? Circulation 2017;136:2245-7.

91. Saxena A, Desai A, Narvencar K, et al. Echocardiographic prevalence of rheumatic heart disease in Indian school children using World Heart Federation criteria A multi site extension of RHEUMATIC study (the e-RHEUMATIC study). Int J Cardiol 2017;249:438-42.

92. Mucumbitsi J, Bulwer B, Mutesa L, et al. Prevalence of rheumatic valvular heart disease in Rwandan school children: echocardiographic evaluation using the World Heart Federation criteria. Cardiovasc J Afr 2017;28:285-92.

93. Nascimento BR, Beaton AZ, Nunes MC, et al. Echocardiographic prevalence of rheumatic heart disease in Brazilian schoolchildren: Data from the PROVAR study. Int J Cardiol 2016;219:439-45.

94. Marijon E, Ou P, Celermajer DS, et al. Prevalence of rheumatic heart disease detected by echocardiographic screening. N Engl J Med 2007;357:470-6.

95. Novick WM, Stidham GL, Karl TR, et al. Paediatric cardiac assistance in developing and transitional countries: the impact of a fourteen year effort. Cardiol Young 2008;18:316-23.

96. Tefera E, Nega B, Yadeta D, et al. Humanitarian Cardiology and Cardiac Surgery in Sub-Saharan Africa: Can We Reshape the Model? World J Pediatr Congenit Heart Surg 2016;7:727-31.

97. Kalangos A. "Hearts for all": a humanitarian association for the promotion of cardiology and cardiac surgery in developing countries. Ann Thorac Surg 2002;73:341-2.

98. Celebrating 50 years of 'Children's Heart Link': Pediatric Heart Surgery - from Minnesota to the World. Available online: https://childrensheartlinkorg/50th-anniversary/

99. Ezri T, Sasson L, Houri S, et al. Save a Child's Heart project in Israel. Lancet 2014;384:1575-6.

100. Cohen AJ, Tamir A, Houri S, et al. Save a child's heart: we can and we should. Ann Thorac Surg 2001;71:462-8.

101. Sasson L, Tamir A, Houri S, et al. Mending Hearts and Building Bridges: The Save a Child's Heart Foundation. J Public Health Manag Pract 2016;22:89-98.

102.Scherman J, Bezuidenhout D, Ofoegbu C, et al. TAVI for low to middle income countries. Eur Heart J 2017;38:1182-4.

103.Scherman J, Ofoegbu C, Myburgh A, et al. Preclinical evaluation of a transcatheter aortic valve replacement system for patients with rheumatic heart disease. EuroIntervention 2019; 15:e975-82.

104.Abidjan Declaration for open-heart surgery development and financing in Sub-Saharan Africa. Available online: http://www.samj.org.za/index.php/samj/article/ view/12400/8601

Cite this article as: Zilla P, Bolman RM 3rd, Boateng P, Sliwa K. A glimpse of hope: cardiac surgery in low- and middle-income countries (LMICs). Cardiovasc Diagn Ther 2020;10(2):336-349. doi: 10.21037/cdt.2019.11.03 